Published in final edited form as:

Clin Gastroenterol Hepatol. 2014 October ; 12(10): 1667-1676.e1. doi:10.1016/j.cgh.2014.01.039.

\title{
Risk of Esophageal Adenocarcinoma Decreases With Height, Based on Consortium Analysis and Confirmed by Mendelian Randomization
}

\author{
Aaron P. Thrift ${ }^{\star} \ddagger$, Harvey A. Risch $§$, Lynn Onstad ${ }^{\star}$, Nicholas J. Shaheen", Alan G. Cassonף, \\ Leslie Bernstein\#, Douglas A. Corley ${ }^{\star *}$, David M. Levine ${ }^{\ddagger \ddagger}$, Wong-Ho Chow§§, Brian J.

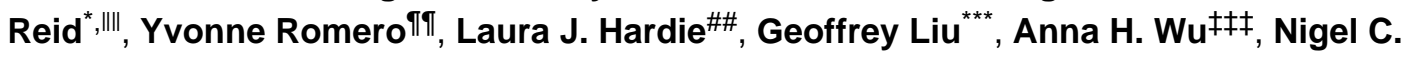

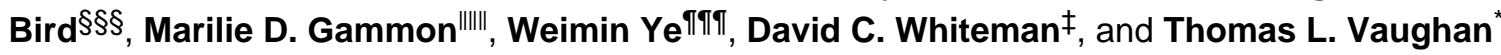 \\ *Division of Public Health Sciences, Fred Hutchinson Cancer Research Center, Seattle, \\ Washington \\ III'Division of Human Biology, Fred Hutchinson Cancer Research Center, Seattle, Washington \\ ¥Cancer Control Group, QIMR Berghofer Medical Research Institute, Brisbane, Queensland, \\ Australia \\ §Department of Chronic Disease Epidemiology, Yale School of Public Health, New Haven, \\ Connecticut \\ "Division of Gastroenterology and Hepatology, University of North Carolina School of Medicine, \\ Chapel Hill, North Carolina \\ "Department of Surgery, University of Saskatchewan, Saskatoon, Canada \\ \#Department of Population Sciences, Beckman Research Institute and City of Hope \\ Comprehensive Cancer Center, Duarte, California \\ **Division of Research and Oakland Medical Center, Kaiser Permanente, Oakland, California \\ ¥łDepartment of Biostatistics, University of Washington School of Public Health, Seattle, \\ Washington \\ $\S \S$ Department of Epidemiology, MD Anderson Cancer Center, Houston, Texas \\ IT'Division of Gastroenterology and Hepatology, Mayo Clinic, Rochester, Minnesota \\ \#\#Division of Epidemiology, University of Leeds, Leeds, United Kingdom \\ ${ }^{* *}$ Division of Medical Oncology and Hematology, Princess Margaret Cancer Centre-Ontario \\ Cancer Institute, University of Toronto, Toronto, Ontario, Canada
}

() 2014 by the AGA Institute

Reprint requests. Address requests for reprints to: Aaron P. Thrift, PhD, Program in Epidemiology, Fred Hutchinson Cancer Research Center, PO Box 19024, M4-B874, Seattle, Washington 98109-1024. athrift @fhcrc.org; fax: (206) 667-4787.

Supplementary Material

Note: To access the supplementary material accompanying this article, visit the online version of Clinical Gastroenterology and Hepatology at www.cghjournal.org, and at http://dx.doi.org/10.1016/j.cgh.2014.01.039.

Conflicts of interest

The authors disclose no conflicts. 
$¥ \neq \ddagger$ Department of Preventive Medicine, University of Southern California Keck School of Medicine, Los Angeles, California

$\S \S \S$ Department of Oncology, The Medical School, University of Sheffield, United Kingdom

IIIIIDepartment of Epidemiology, University of North Carolina School of Public Health, Chapel Hill, North Carolina

ศTI Department of Medical Epidemiology and Biostatistics, Karolinska Institutet, Stockholm, Sweden

\section{Abstract}

BACKGROUND \& AIMS—Risks for some cancers increase with height. We investigated the relationship between height and risk of esophageal adenocarcinoma (EAC) and its precursor, Barrett's esophagus (BE).

METHODS-We analyzed epidemiologic and genome-wide genomic data from individuals of European ancestry in the Barrett's and Esophageal Adenocarcinoma Consortium, from 999 cases of EAC, 2061 cases of BE, and 2168 population controls. Multivariable logistic regression was used to estimate odds ratios (OR) and $95 \%$ confidence intervals $(95 \% \mathrm{CI})$ for associations between height and risks of EAC and BE. We performed a Mendelian randomization analysis to estimate an unconfounded effect of height on EAC and BE using a genetic risk score derived from 243 genetic variants associated with height as an instrumental variable.

RESULTS-Height was associated inversely with EAC (per 10-cm increase in height: OR, 0.70; 95\% CI, 0.62-0.79 for men and OR, 0.57; 95\% CI 0.40-0.80 for women) and BE (per 10-cm increase in height: OR, $0.69 ; 95 \%$ CI, $0.62-0.77$ for men and OR, $0.61 ; 95 \%$ CI, $0.48-0.77$ for women). The risk estimates were consistent across strata of age, education level, smoking, gastroesophageal reflux symptoms, body mass index, and weight. Mendelian randomization analysis yielded results quantitatively similar to those from the conventional epidemiologic analysis.

CONCLUSIONS-Height is associated inversely with risks of EAC and BE. Results from the Mendelian randomization study showed that the inverse association observed did not result from confounding factors. Mechanistic studies of the effect of height on EAC and BE are warranted; height could have utility in clinical risk stratification.

\section{Keywords}

Esophageal Cancer; Etiology; Risk Factors; Sex Differences

Esophageal adenocarcinoma (EAC) incidence increased 8-fold in the United States from 1973 to $2008 .{ }^{1}$ Incidence is up to 8 -fold higher in males than in females ${ }^{2}$; however, incidence rates for EAC continue to increase in both males and females. ${ }^{1}$ It is presumed that almost all cases of EAC arise within a metaplastic epithelium of the esophagus known as Barrett's esophagus (BE). Gastroesophageal reflux (GER), obesity, and, to a lesser extent, tobacco smoking are the primary risk factors for EAC and BE. ${ }^{3-7}$ On the other hand, CagApositive Helicobacter pylori colonization and regular use of aspirin and nonsteroidal antiinflammatory drugs are associated with reduced risks. ${ }^{8-11} \mathrm{~A}$ better understanding of risk 
factors for EAC may allow for both improved risk stratification and better insight into the pathogenesis of this lethal condition.

Recently, attention has focused on the relationship between attained height and cancer. A 2011 meta-analysis of 11 prospective studies found that the risk of all cancers combined increased by $10 \%$ and $15 \%$ per $10-\mathrm{cm}$ increase in height in males and females, respectively. ${ }^{12}$ Indeed, height may explain up to one half of the excess risks for all cancers in males. ${ }^{13}$ Furthermore, height also is associated with increased risk of all-cancer mortality. ${ }^{14}$ Although height is an independent risk factor and prognostic factor for cancers of the colorectum, breast, endometrium, prostate, ovary, and melanoma, studies have reported an inverse association between height and gastric cancer and with cancers of the head and neck. ${ }^{14-16}$

The association between height and esophageal cancer is unclear. In the largest studies to date, height was not associated with the risk of esophageal cancer in the Million Women Study ${ }^{12}$ or with mortality from esophageal cancer in the Emerging Risk Factor Collaboration study. ${ }^{14}$ However, the association with height may vary by histologic subtype because EAC and esophageal squamous cell carcinoma (ESCC) have different risk profiles. Height partly may explain the sex difference for EAC, although few studies have considered EAC and ESCC separately in relation to height, and those that have done so were limited by small numbers of cases. Height was associated inversely with risks of EAC and ESCC in one study, ${ }^{17}$ whereas in another study height was associated inversely with EAC but not with ESCC. ${ }^{18}$ In the National Institutes of Health AARP Diet and Health Study, there was evidence of an inverse association between height and EAC, although this did not reach statistical significance. ${ }^{19}$ In a prospective study in the general Norwegian population, a statistically significant inverse association was observed between height and both EAC and ESCC risks in males. In females, a similar relationship (albeit weaker and not statistically significant) was seen for EAC but not ESCC. ${ }^{20}$ For BE, there was no association with height in 2 previous studies. ${ }^{21,22}$ In this study, we aimed to clarify the association between height and risks of $\mathrm{EAC}$ and $\mathrm{BE}$.

We took advantage of epidemiologic and genome-wide genomic data available from a large international consortium of BE and EAC studies-the Barrett's and Esophageal Adenocarcinoma Consortium (BEACON, http://beacon.tlvnet.net/). We undertook a pooled analysis of original epidemiologic data from 14 population-based case-control and cohort studies in BEACON to examine the association between height and risks of EAC and BE. Because attained height varies by or is influenced by sex, smoking, socioeconomic status, and various early life exposures, the risk estimates for the height-EAC and height-BE associations obtained from conventional epidemiologic analyses may be confounded. We therefore additionally performed a Mendelian randomization analysis using a genetic risk score (GRS) (derived from 243 single-nucleotide polymorphisms [SNPs] associated with height in European populations) (Wood AR et al, unpublished data, 2013) as an instrumental variable (IV) for height to obtain unconfounded risk estimates for height-EAC and heightBE associations..$^{23-25}$ The IV method helps to overcome confounding because alleles are allocated randomly from parents to offspring and are not associated with the wide range of 
risk factors that may confound the association with height. ${ }^{23,24,26}$ Further, the genetic variants are measured reliably and are not affected by disease status or by study design. ${ }^{27}$

\section{Methods}

\section{Study Population}

Data concerning EAC and BE cases and controls were obtained from 14 epidemiologic studies in BEACON. To avoid confounding from population stratification, we restricted our analyses to individuals of European ancestry (confirmed in samples using principal components analysis) that were included in the recent genome-wide association study conducted by BEACON (Barrett's and Esophageal Adenocarcinoma Genetic Susceptibility Study). ${ }^{28}$ Histologic confirmation of EAC was performed for all EAC studies. ${ }^{6}$ Similarly, $\mathrm{BE}$ was confirmed histologically via identification of goblet cells in metaplastic columnar epithelium in a biopsy sample taken from the esophagus. ${ }^{7}$ A total of 1516 EAC cases, 2416 BE cases, and 2187 controls were available for pooling. We excluded participants with missing information on weight or height (517 EAC cases, $355 \mathrm{BE}$ cases, and 18 controls) and those with extreme values ( 1 male control with height $<130 \mathrm{~cm}$ ). Analyses thus were based on 999 EAC cases, 2061 BE cases, and 2168 controls (Table 1). The study was approved by the institutional review boards or research ethics committees of each participating institution.

\section{Statistical Analysis}

The exposure and outcome data from the 14 studies were pooled and analyses of the single data set were performed separately for EAC and BE and by sex. Self-reported current height (at the time of interview) was the main exposure. Unconditional multivariable logistic regression models were used to estimate odds ratios (ORs) and 95\% confidence intervals (CIs) for the association between height and risk of EAC/BE, adjusted for factors significantly associated with EAC/BE in the BEACON data set. We examined the association of height categorized into quartiles based on the distribution among controls (males: $<173,173$ to $<178,178$ to $<182$, and $\geq \mathrm{cm}$; females: $<158,158$ to $<163,163$ to $<168$, and $\geq 168 \mathrm{~cm}$ ), and also computed the OR for EAC and BE per 10-cm increase in height as a continuous variable. To estimate the independent effect for height, we adjusted our analyses by factors known to be associated with EAC and BE. Instead of adjusting for weight or body mass index (BMI), which are associated with EAC and BE and appreciably correlated with height, we used a weight-for-height variable $\left(\mathrm{W} / \mathrm{H}^{x}\right)$ for such values of $x$ that $\mathrm{W} / \mathrm{H}^{x}$ was highly correlated with weight (Pearson correlation coefficient, $r$, close to 1 ) but not correlated with height ( $r$ close to 0$).{ }^{29}$ In our population, the optimal factor was $x=1.8$ for males (weight, $r=0.91$; height, $r=-0.005$ ) and $x=1.5$ for females (weight, $r=0.96$; height, $r=-0.002$ ). The fully adjusted models also included terms for age (categoric: $<50$, $50-59,60-69, \geq 70 \mathrm{y}$ ), education (<high school vs thigh school), cigarette smoking status (ever vs never), and reported GER symptom status (ever vs never). Participants with missing data for covariables were included in the analyses using an additional category for missing values. We examined potential nonlinearity of the association with height (continuous) with penalized splines in generalized additive logistic models adjusted for the same covariables. To assess possible effect modification, we performed stratified analyses by age, education, 
smoking status, GER symptoms, BMI, and weight. We included an interaction term in the full model to assess the statistical significance of the differences in association across strata. Finally, to evaluate potential differences in the associations across studies, we also obtained summary risk estimates for height using a 2-stage approach among studies with data available from both cases and controls: we first estimated study-specific ORs and associated 95\% CIs, and then combined them using a random-effects meta-analytic model to calculate a summary OR. Between-study heterogeneity was assessed using the $I^{2}$ statistic.

\section{Mendelian Randomization: Instrumental Variable Analysis}

Genotyping of DNA from buffy coat or whole blood was performed using the Illumina HumanOmni1-Quad platform (Illumina, San Diego, CA) as previously described. ${ }^{28}$ Call rates were $95 \%$ or higher and all SNPs were in Hardy-Weinberg equilibrium over controls given an a value of .0001. A recent genome-wide association study for height conducted by the Genetic Investigation of ANthropometric Traits (GIANT) consortium identified 697 independent SNPs associated with height at genome-wide significance $\left(P<5 \times 10^{-8}\right)$ (Wood AR et al, unpublished data, 2013). We used genotype information from 243 SNPs common to the genotyping array used by both BEACON and GIANT to derive a weighted GRS as an IV for height. For each SNP, participants received a score of 0,1 , or 2 for carrying 0 (homozygous unassociated), 1 (heterozygous), or 2 (homozygous associated) height-increasing risk alleles, and SNP GRS components were weighted by the per-allele change in height (the increase in centimeters per 1 additional risk allele) reported for that SNP in the genome-wide association study for height (Wood AR et al, unpublished data, 2013). Of 5228 participants, 4736 had complete genotype data on all 243 SNPs, 444 had genotype data on 242 SNPs, and the remaining 48 had genotype data on at least 231 SNPs; we imputed genotype data on those 492 participants with missing SNP data using mean replacement.

The IV effect of height on risk of EAC/BE was estimated using the weighted GRS under an additive model and the 2-stage control function IV method. ${ }^{30}$ By using controls only, we first predicted height from the weighted GRS. In the second stage, we regressed case-control status on the predicted values of height, the coefficient of which is the estimated effect of height on EAC/BE. We used the F-statistic from the first-stage regression to assess the strength of the instrument $(\mathrm{F}>10$ indicates sufficient strength to ensure the validity of the IV method ${ }^{31}$ ). The estimates from the multivariable and IV analyses then were compared using the Durbin form of the Durbin-Wu-Hausman statistic, ${ }^{32}$ in which rejection of the null hypothesis indicates that the 2 risk estimates for height are not equal.

All analyses were performed using Stata 13.0 (Stata-Corp LP, College Station, TX). Statistical tests were 2 -sided and $P$ values less than .05 were considered statistically significant.

\section{Results}

Overall, 4134 males (1704 controls, 883 EAC cases, and 1547 BE cases) and 1094 females (464 controls, 116 EAC cases, and 514 BE cases) from 14 studies were included in these analyses. The numbers of cases and controls, and summary data for height by study are 
shown in Table 1. The mean height among male and female controls was $177.2 \mathrm{~cm}(\mathrm{SD}, 6.9)$ and $163.1 \mathrm{~cm}$ (SD, 6.4), respectively, whereas BE cases (males: $175.7 \mathrm{~cm}$; SD, $7.3 \mathrm{~cm}$; females: $161.4 \mathrm{~cm}$; SD, $6.5 \mathrm{~cm}$ ) and EAC cases (males: $175.2 \mathrm{~cm}$; SD, 7.2; females: 160.3 $\mathrm{cm}$; $\mathrm{SD}, 7.7 \mathrm{~cm}$ ) were shorter on average than controls. As expected, cases were significantly more likely than controls to be obese, have ever smoked, and have had GER symptoms (Table 2).

In the pooled analysis, we observed statistically significant inverse associations between height and the risks of EAC and BE (Table 3). For males, the age-adjusted risks for EAC and BE per 10-cm increase in height were as follows: 0.67 (95\% CI, 0.60-0.76) and 0.71 (95\% CI, 0.65-0.79), respectively. After adjusting for age, education, smoking status, $\mathrm{W} / \mathrm{H}^{x}$, and GER symptoms, the OR was 0.70 (95\% CI, 0.62-0.79) for EAC and 0.69 (95\% CI, 0.62-0.77) for BE. Compared with males in the lowest quartile, males in the highest quartile of height had a 52\% (OR, 0.48; 95\% CI, 0.38-0.62) lower risk of EAC and a 47\% (OR, 0.53 ; 95\% CI, 0.43-0.66) lower risk of BE. The results were unchanged when BMI was included in the models instead of $\mathrm{W} / \mathrm{H}^{x}$ (data not shown). In an analysis of a subset of participants with waist-to-hip ratio data $(n=1123$ participants from 5 studies $)$, the magnitude of the height-BE inverse association was the same when we adjusted for waist-tohip ratio instead of $\mathrm{W} / \mathrm{H}^{\mathrm{x}}$ (data not shown). Among females, the OR per $10-\mathrm{cm}$ increase in height was 0.57 (95\% CI, 0.40-0.80) for EAC and 0.61 (95\% CI, 0.48-0.77) for BE in the fully adjusted model. The ORs did not differ significantly by sex $($ EAC: $P$ interaction $=.16$; BE: $P$ interaction $=.55)$, and the models suggested an inverse, linear, dose-response relationship between height and both $\mathrm{BE}$ and EAC (ie, the restricted cubic spline models [Figure 1] showed no consistent evidence of a nonlinear relationship; EAC: males, $P$ nonlinearity $=.55$; females, $P$ nonlinearity $=.02$; BE: males, $P$ nonlinearity $=.23$; females, $P$ nonlinearity $=.59)$.

Similar results were found using random-effects models (Supplementary Figure 1) that included only studies with both center-specific cases and controls (EAC risk per 10-cm increase in height: males, fully adjusted summary OR, $0.73 ; 95 \% \mathrm{CI}, 0.62-0.86 ; I^{2}=0 \%$; females, fully adjusted summary OR, $0.76 ; 95 \% \mathrm{CI}, 0.46-1.25 ; I^{2}=0 \%$; BE risk per $10-\mathrm{cm}$ increase in height: males, fully adjusted summary OR, $0.84 ; 95 \% \mathrm{CI}, 0.72-1.00, I^{2}=0 \%$; females, fully adjusted summary OR, $0.75 ; 95 \% \mathrm{CI}, 0.53-1.05 ; I^{2}=0 \%$ ).

As expected, among both male and female controls, the mean heights were greater among younger persons ( $<50$ vs $\geq 50 \mathrm{y}$ ) and those with higher levels of education ( $<$ high school vs thigh school). Nevertheless, the association of height with EAC and BE did not vary by age (males: EAC $P$ interaction $=.69, \mathrm{BE} P$ interaction $=.38$; females: $\mathrm{EAC} P$ interaction $=.97$, BE $P$ interaction $=.13$ ), or education level (males: EAC $P$ interaction $=.38$, BE $P$ interaction $=.08$; females: $\mathrm{EAC} P$ interaction $=.34, \mathrm{BE} P$ interaction $=.85$ ). The inverse associations between height and $\mathrm{EAC}$ and $\mathrm{BE}$ also were consistent across strata of smoking, GER symptoms, BMI, and weight (Figure 2).

\section{Instrumental Variable Analysis}

Among males, the weighted GRS ranged from 6.04 to 8.11 (mean, 7.0; SD, 0.28) in controls, the range was 5.92 to 7.95 (mean, 6.9; SD, 0.28) in EAC cases and 6.06 to 7.99 
(mean, 7.0; SD, 0.28) in BE cases. Among females, the weighted GRS ranged from 6.01 to 7.80 (mean, 7.0; SD, 0.29) in controls, 6.31 to 7.83 (mean, 7.0; SD, 0.30) in EAC cases and 6.10 to 7.75 (mean, 7.0; SD, 0.31) in BE cases. In controls and cases, the GRS was normally distributed. Average height increased with increasing weighted GRS and was generally higher in controls than in cases over the range of the GRS (Figure 3). As anticipated (based on the principle of Mendelian randomization), the weighted GRS was not associated with potential confounders including age $(P=.57)$, sex $(P=.69)$, education level $(P=.77)$, smoking status $(P=.36)$, waist-to-hip ratio $(P=.96)$, and GER symptoms $(P=.47)$. The weighted GRS was a strong predictor of height (males: F-statistic, 142.5; females: Fstatistic, 27.1). In the IV analyses, each 10-cm increase in height was associated with a $27 \%$ lower risk of EAC (IV OR, 0.73; 95\% CI, 0.46-1.15) and an 11\% lower risk of BE (IV OR, $0.89 ; 95 \%$ CI, 0.60-1.31) in males, and a 37\% lower risk of EAC (IV OR, $0.63 ; 95 \%$ CI, 0.15-2.63) and a 39\% lower risk of BE (IV OR, 0.61; 95\% CI, 0.27-1.39) in females; although these did not reach statistical significance. The magnitude of the ORs in the IV analyses were similar to those obtained from the epidemiologic analyses (Durbin-WuHausman test of difference between ORs from conventional methods and ORs from IV methods: males, EAC, $P=.82$; BE, $P=.18$; females: EAC, $P=.99$; $\mathrm{BE}, P=.98$ ).

\section{Discussion}

The results from this large pooled analysis of epidemiologic and genetic data from 14 studies show a consistent inverse association between height and risks of EAC and BE. The ORs for EAC and BE per 10-cm increase in height were 0.70 (95\% CI, 0.62-0.79) and 0.69 (95\% CI, 0.62-0.77) for males, and 0.57 (95\% CI, 0.40-0.80) and 0.61 (95\% CI, 0.48-0.77) for females, respectively. Although the point estimates in females were of stronger magnitude, there were no statistically significant interactions between height, sex, and disease risk. Adjustment for a range of potential confounders attenuated the risk estimates somewhat, however, the inverse associations remained strong, statistically significant, and consistent within all strata of examined potential effect modifiers. Furthermore, the similarity in effects obtained from the conventional observational epidemiologic approach compared with those obtained from the Mendelian randomization approach, using a weighted GRS as an IV for height, suggests that the former was unlikely to be affected by residual confounding.

Greater height is associated with increased risk of all cancers combined and with risk of death from cancer. In the Million Women Study, total cancer risk increased by $16 \%$ per 10$\mathrm{cm}$ increase in height. ${ }^{12}$ A similar result was found in a cohort of about 90,000 female Canadians (13\% increase per 10-cm increase in height) ${ }^{33}$ and among males and females in the Vitamins and Lifestyle Study (12\% increase per 10-cm increase in height). ${ }^{13}$ In the Emerging Risk Factor Collaboration study, risk of cancer-related death increased by $6 \%$ per $10-\mathrm{cm}$ increase in height. ${ }^{14}$ However, not all cancers are associated with height and the magnitude of the excess risk varies by cancer site (the greatest excess risk was seen for melanoma). ${ }^{12,33}$ Height has been associated inversely with mortality from gastric cancer, ${ }^{14}$ and in a pooled analysis of 24 studies of head and neck cancers, an inverse association was seen with height (10\% and $15 \%$ reduced risk per 10-cm increase in height in males and females, respectively). ${ }^{16}$ Height was not associated with esophageal cancer (all subtypes 
combined) in the Million Women Study or in the Emerging Risk Factor Collaboration study. However, epidemiologic studies have shown that the major histologic subtypes of esophageal cancer (EAC and ESCC) have different risk factor profiles. Our results are consistent with those from previous studies examining the height association by esophageal cancer subtypes, ${ }^{17-20}$ showing an inverse relationship between height and EAC. By contrast to 2 previous studies, ${ }^{21,22}$ we found an inverse association between height and risk of BE.

Height itself is not considered a causal (or protective) factor for cancer, but rather a proxy for exposures that affect cancer risk. An increased risk of cancer in taller individuals has been suggested to be the result of higher cell turnover (mediated by steroid hormones or growth factors) or a higher risk of malignant transformation among greater numbers of cells. ${ }^{34}$ It is not intuitively obvious how height may reduce cancer risk. Instead, investigators have proposed that inverse associations may be explained partly, if not entirely, by confounding. For gastric cancer, H pylori colonization may confound the inverse association with height because $H$ pylori is associated with lower socioeconomic status (and thus shorter attained height) and is related causally to gastric cancer. In a subset of BEACON controls with data on $H$ pylori colonization, we found that seropositive controls were shorter on average than negative controls. However, $H$ pylori colonization is associated inversely with EAC and $\mathrm{BE},{ }^{10,11}$ and adjusting for $H$ pylori status strengthened the inverse association with height.

Childhood nutrition, illness, socioeconomic status, and other early life exposures are important determinants of attained height. ${ }^{35}$ Although we adjusted for a wide range of potential confounders, residual confounding may have occurred in our multivariable analyses. We adjusted for known risk factors including past history of reflux and smoking status. Because exposure data were pooled from numerous studies, we used dichotomized variables. Although reducing the data in this way may have led to some residual confounding, this is preferable to dropping observations or variables owing to incomplete data. Nevertheless, risk estimates derived from Mendelian randomization methods are not affected by confounding. Therefore, although the CIs from the IV analyses did include the null, the similarity of the point estimates from both conventional and IV analyses provide evidence that the inverse associations between height and risks of EAC and BE from conventional analyses are unlikely to be caused by confounding.

We can only speculate as to how shorter stature is associated with increased risks of EAC and BE. It is possible that shorter people have greater intra-abdominal pressure, promoting development of a hiatal hernia and subsequent GER. We found tentative evidence to support this hypothesis using the BEACON data set, in which we observed shorter average height among controls with a hiatal hernia compared with controls without. Interestingly, however, stratification of our cohort by the presence of GER symptoms did not show any significant attenuation of the associations among those without GER symptoms, as might be expected if promotion of GER were the sole mechanism by which height was related inversely to BE and EAC. It also is tenable that shorter people may be more easily obese than taller people. In any event, the inverse associations between height and disease risk remained in our analyses, even after adjusting for body mass. 
Regardless of the mechanism, the association we report has potential clinical utility. The prevention of EAC is hindered by a lack of predictors of both BE and EAC. The only risk factor commonly used in clinical practice, the presence of GER symptoms, is neither sensitive nor specific. The identification of further risk factors may allow construction of more sophisticated and accurate risk stratification models, which may, in turn, be used to decide who should undergo endoscopic screening for these conditions. Early attempts at such models report modest performance characteristics, in part owing to the relatively weak association of their predictor variables with the outcomes of interest. ${ }^{36-38}$

In summary, height was associated inversely with risks of EAC and BE, both in men and women. These associations are unlikely to be explained entirely by confounding from known risk factors, or through effect modification by any of a large number of risk factors. Future investigations into why EAC and BE develop in only a subset of people who are obese and/or have frequent GER symptoms should consider the role of height. Mechanistic studies of the effect of height on the risks of BE and EAC are warranted, and this risk factor may have utility in clinical risk stratification.

\section{Supplementary Material}

Refer to Web version on PubMed Central for supplementary material.

\section{Acknowledgments}

The authors thank Georgia Green, Patricia Christopherson, Paul Hansen, Lorna Nolan, and Terri Watson for their efforts in project management and organization of biospecimens and data. The authors also thank the members of the Mayo Clinic Esophageal Adenocarcinoma and Barrett's Esophagus Registry Consortium ( ${ }^{1}$ Mayo Clinic, Florida, ${ }^{2}$ Mayo Clinic, Rochester, ${ }^{3}$ Mayo Clinic, Arizona): Sami R. Achem, MD ${ }^{1}$ Yvonne Romero, MD, ${ }^{2}$ David A. Ahlquist, $\mathrm{MD},{ }^{2}$ Steven R. Alberts, MD ${ }^{2}$ Jeffrey A. Alexander, MD, ${ }^{2}$ Mark S. Allen, MD, ${ }^{2}$ Amindra S. Arora, MBBChir, ${ }^{2}$ Jonathan B. Ashman, MD, PhD, ${ }^{3}$ Pamela J. Atherton, MS, ${ }^{2}$ Lisa A. Boardman, MD, ${ }^{2}$ Ernest P. Bouras, MD, ${ }^{1}$ Vicki A. Bryhn, ${ }^{2}$ Patrick A. Burch, MD, ${ }^{2}$ George E. Burdick, MD,${ }^{2}$ Navtej S. Buttar, MD, ${ }^{2}$ John K. Camoriano, MD ${ }^{3}$ John R. Cangemi, MD, ${ }^{1}$ Stephen D. Cassivi, MD, ${ }^{2}$ Frances K. Cayer, CCRP, ${ }^{1}$ Amy C. Clayton, $\mathrm{MD},{ }^{2}$ Michael D. Crowell, MD, PhD, ${ }^{3}$ Julie M. Cunningham, $\mathrm{PhD},{ }^{2}$ Mariza de Andrade, $\mathrm{PhD},{ }^{2}$ Piet de Groen, MD, ${ }^{2}$ Giovani De Petris, MD, ${ }^{3}$ Claude Deschamps, MD, ${ }^{2}$ Kenneth R. DeVault, MD, ${ }^{1}$ Robert B. Diasio, MD, ${ }^{2}$ John K. DiBaise, MD, ${ }^{3}$ Eric S. Edell, MD, ${ }^{2}$ Sharon Elcombe, ${ }^{2}$ Charles Erlichman, MD, ${ }^{2}$ Douglas O. Faigel, MD, ${ }^{3}$ Tom R. Fitch, MD, ${ }^{3}$ David E. Fleischer, MD, ${ }^{3}$ Jean C. Fox, MD, ${ }^{2}$ Amy E. Foxx-Orenstein, DO, ${ }^{2}$ Dawn Francis, MD, ${ }^{2}$ Mary B. Fredericksen, CCRP, ${ }^{2}$ Evanthia Galanis, MD, ${ }^{2}$ Debra M. Geno, ${ }^{2}$ Axel Grothey, MD, ${ }^{2}$ Michael G. Haddock, MD, ${ }^{2}$ Kevin C. Halling, MD, PhD ${ }^{2}$ Denise M. Harnois, DO, ${ }^{1}$ Tracy W. Hilton, BS, ${ }^{1}$ Timothy Hobday, MD, ${ }^{2}$ Lesley A. Houghton, PhD, ${ }^{1}$ Prasad A. Iyer, MD, ${ }^{2}$ Dawn E. Jaroszewski, MD, ${ }^{3}$ Aminah Jatoi, MD, ${ }^{2}$ Robert B. Jenkins, MD, PhD, ${ }^{2}$ Elizabeth A. Johnson, MD, ${ }^{1}$ Rajni Katipamula, MD, ${ }^{2}$ David A. Katzka, MD, ${ }^{2}$ Sharon F. Kaufman, ${ }^{2}$ Andrew P. Keaveny, MD, ${ }^{1}$ Daniel A. Keller, ${ }^{2}$ George P. Kim, MD, ${ }^{1}$ Benjamin R. Kipp, PhD, ${ }^{2}$ Dora M. Lam-Himlin, MD, ${ }^{2}$ Stephen M. Lange, MD, ${ }^{1}$ Louis Lanza, MD, ${ }^{3}$ Shauna N. Legrand, BS, ${ }^{1}$ Paul J. Limburg, $\mathrm{MD},{ }^{2}$ Wilma L. Lingle, PhD, ${ }^{2}$ Wanguo Liu, PhD ${ }^{2}$ G. Richard Locke III, MD, ${ }^{2}$ David S. Loeb, MD, ${ }^{1}$ Lori S. Lutzke, CCRP, ${ }^{2}$ James A. Martenson Jr, MD, ${ }^{2}$ Robert R. McWilliams, MD ${ }^{2}$ Robert C. Miller, MD, ${ }^{2}$ Joseph A. Murray, MD, ${ }^{2}$ Cuong C. Nguyen, MD,${ }^{3}$ Francis C. Nichols III, MD, ${ }^{2}$ John A. Odell, MD, ${ }^{1}$ Rahul Pannala, MD, ${ }^{3}$ Harshita R. Paripati, MD, ${ }^{2}$ Alexander S. Parker, PhD, ${ }^{1}$ Shabana F. Pasha, MD, ${ }^{2}$ Bret T. Petersen, MD, ${ }^{2}$ Gloria M. Petersen, PhD, ${ }^{2}$ Michael F. Picco, MD, ${ }^{1}$ Henry C. Pitot, MD,${ }^{2}$ J. Fernando Quevedo, MD, ${ }^{2}$ Massimo Raimondo, $\mathrm{MD},{ }^{1}$ Elizabeth Rajan, MD, ${ }^{2}$ Francisco (Pancho) C. Ramirez, MD, ${ }^{2}$ Renee M. Root, BS, CT(ASCP) ${ }^{2}$ Helen J. Ross, MD, ${ }^{3}$ Joseph Rubin, MD, ${ }^{2}$ Schuyler O. Sanderson, MD, ${ }^{2}$ Daniel J. Sargent, PhD, ${ }^{2}$ Daniel J. Schaid, PhD, ${ }^{2}$ K. Robert Shen, MD, ${ }^{2}$ Qian Shi, PhD, ${ }^{2}$ Frank A. Sinicrope, MD, ${ }^{2}$ Jeff A. Sloan, PhD, ${ }^{2}$ Dan C. Smith, MD, ${ }^{1}$ David I. Smith, PhD, ${ }^{2}$ Thomas C. Smyrk, MD, ${ }^{2}$ Mark E. Stark, MD ${ }^{1}$ Nicholas Talley, MD, PhD, ${ }^{2}$ Stephen N. Thibodeau, PhD, ${ }^{2}$ Michael D. Van Norstrand, MD, PhD,${ }^{2}$ Michael B. Wallace, MD, ${ }^{1}$ Kenneth K. Wang, MD, ${ }^{2}$ Richard M. Weinshilboum, MD, ${ }^{2}$ Dennis Wigle, MD, PhD, ${ }^{2}$ Herbert C. Wolfsen, MD, ${ }^{1}$ Louis M. Wong Kee Song, $\mathrm{MD},{ }^{2}$ Timothy A. Woodward, MD, ${ }^{1}$ Tsung-The Wu, MD, PhD,${ }^{2}$ Harry H. Yoon, MD ${ }^{2}$ and Alan R. Zinsmeister, $\mathrm{PhD}^{2}$

Yvonne Romero participated in the study on behalf of the Mayo Clinic Esophageal Adenocarcinoma and Barrett's Esophagus Registry Consortium. 
Funding

Supported primarily by a National Institutes of Health grant (R01CA136725). Also supported by Travel Fellowships from the European Association for Cancer Research and the University of Queensland and an Early Career Fellowship from the National Health and Medical Research Council of Australia (APP1052219) (A.P.T.); by a grant from the National Institutes of Health (P30 DK034987 to N.J.S.); by a grant from the National Institutes of Health (National Institutes for Diabetes and Digestive and Kidney Diseases 02956), the Robert Wood Johnson Foundation Harold Amos Medical Faculty Development Program, and the Fraternal Order of the Eagles (Y.R.); by the Alan B. Brown Chair in Molecular Genomics and by the CCO Chair in Experimental Therapeutics and Population Studies (G.L.); by a National Institute of Health Career Development Award (K05CA124911 to T.L.V.); and by a Future Fellowship from the Australian Research Council (FT0990987 to D.C.W.).

Additional study specific support was provided by The California Tobacco Related Research Program (3RT-0122 Q5 and 10RT-0251); the Swedish Cancer Society (4559-B01-01XAA and 4758-B02-01XAB); and the US National Institutes of Health (P01CA091955, R01CA072866, R01CA57947, R01CA59636, R01CA100264, P30CA016672, R01CA133996, P50CA093459, U01CA57949, U01CA57983, U01CA57923, and R01DK63616).

The Mayo Clinic Esophageal Adenocarcinoma and Barrett's Esophagus Registry Consortium is supported in part by the American Digestive Health Foundation Endoscopic Research Award, the American College of Gastroenterology Junior Faculty Development Award, the Glaxo Wellcome, Inc, Institute for Digestive Health Clinical Research Award, and the Miles and Shirley Fiterman Center for Digestive Diseases at Mayo Clinic, Rochester, Minnesota. The Esophageal Adenocarcinoma and Barrett's Esophagus Registry also has received charitable gifts from 5 industry partners (Affymetrix, AstraZeneca, Santarus, Takeda, and Wyeth).

The funders of the study had no role in the design, analysis, or interpretation of the data, or in writing or publication decisions related to this article.

\section{Abbreviations used in this paper}

$\begin{array}{ll}\text { BE } & \text { Barrett's esophagus } \\ \text { BEACON } & \text { Barrett's and Esophageal Adenocarcinoma Consortium } \\ \text { BMI } & \text { body mass index } \\ \text { CI } & \text { confidence interval } \\ \text { EAC } & \text { esophageal adenocarcinoma } \\ \text { ESCC } & \text { esophageal squamous cell carcinoma } \\ \text { GER } & \text { gastroesophageal reflux } \\ \text { GRS } & \text { genetic risk score } \\ \text { IV } & \text { instrumental variable } \\ \text { OR } & \text { odds ratio } \\ \text { SNP } & \text { single-nucleotide polymorphism }\end{array}$

\section{References}

1. Thrift AP, Whiteman DC. The incidence of esophageal adenocarcinoma continues to rise: analysis of period and birth cohort effects on recent trends. Ann Oncol. 2012; 23:3155-3162. [PubMed: 22847812]

2. Cook MB, Chow WH, Devesa SS. Oesophageal cancer incidence in the United States by race, sex, and histologic type, 1977-2005. Br J Cancer. 2009; 101:855-859. [PubMed: 19672254]

3. Lagergren J, Bergstrom R, Lindgren A, et al. Symptomatic gastroesophageal reflux as a risk factor for esophageal adenocarcinoma. N Engl J Med. 1999; 340:825-831. [PubMed: 10080844] 
4. Hoyo C, Cook MB, Kamangar F, et al. Body mass index in relation to oesophageal and oesophagogastric junction adenocarcinomas: a pooled analysis from the International BEACON Consortium. Int J Epidemiol. 2012; 41:1706-1718. [PubMed: 23148106]

5. Kubo A, Cook MB, Shaheen NJ, et al. Sex-specific associations between body mass index, waist circumference and the risk of Barrett's oesophagus: a pooled analysis from the international BEACON consortium. Gut. 2013; 62:1684-1691. [PubMed: 23355549]

6. Cook MB, Kamangar F, Whiteman DC, et al. Cigarette smoking and adenocarcinomas of the esophagus and esophagogastric junction: a pooled analysis from the international BEACON consortium. J Natl Cancer Inst. 2010; 102:1344-1353. [PubMed: 20716718]

7. Cook MB, Shaheen NJ, Anderson LA, et al. Cigarette smoking increases risk of Barrett's esophagus: an analysis of the Barrett's and Esophageal Adenocarcinoma Consortium. Gastroenterology. 2012; 142:744-753. [PubMed: 22245667]

8. Liao LM, Vaughan TL, Corley DA, et al. Nonsteroidal anti-inflammatory drug use reduces risk of adenocarcinomas of the esophagus and esophagogastric junction in a pooled analysis. Gastroenterology. 2012; 142:442-452. [PubMed: 22108196]

9. Anderson LA, Johnston BT, Watson RG, et al. Nonsteroidal anti-inflammatory drugs and the esophageal inflammation-metaplasia-adenocarcinoma sequence. Cancer Res. 2006; 66:4975-4982. [PubMed: 16651456]

10. Whiteman DC, Parmar P, Fahey P, et al. Association of Helicobacter pylori infection with reduced risk for esophageal cancer is independent of environmental and genetic modifiers. Gastroenterology. 2010; 139:73-83. [PubMed: 20399210]

11. Thrift AP, Pandeya N, Smith KJ, et al. Helicobacter pylori infection and the risks of Barrett's oesophagus: a population-based case-control study. Int J Cancer. 2012; 130:2407-2416. [PubMed: 21681741]

12. Green J, Cairns BJ, Casabonne D, et al. Height and cancer incidence in the Million Women Study: prospective cohort, and meta-analysis of prospective studies of height and total cancer risk. Lancet Oncol. 2011; 12:785-794. [PubMed: 21782509]

13. Walter RB, Brasky TM, Buckley SA, et al. Height as an explanatory factor for sex differences in human cancer. J Natl Cancer Inst. 2013; 105:860-868. [PubMed: 23708052]

14. The Emerging Risk Factors Collaboration. Adult height and the risk of cause-specific death and vascular morbidity in 1 million people: individual participant meta-analysis. Int J Epidemiol. 2012; 41:1419-1433. [PubMed: 22825588]

15. Davey Smith G, Hart C, Upton M, et al. Height and risk of death among men and women: aetiological implications of associations with cardiorespiratory disease and cancer mortality. $\mathrm{J}$ Epidemiol Community Health. 2000; 54:97-103. [PubMed: 10715741]

16. Leoncini E, Ricciardi W, Cadoni G, et al. Adult height and head and neck cancer: a pooled analysis within the INHANCE Consortium. Eur J Epidemiol. 2014; 29:35-48. [PubMed: 24271556]

17. Lagergren J, Bergstrom R, Nyren O. Association between body mass and adenocarcinoma of the esophagus and gastric cardia. Ann Intern Med. 1999; 130:883-890. [PubMed: 10375336]

18. Chow WH, Blot WJ, Vaughan TL, et al. Body mass index and risk of adenocarcinomas of the esophagus and gastric cardia. J Natl Cancer Inst. 1998; 90:150-155. [PubMed: 9450576]

19. O'Doherty MG, Freedman ND, Hollenbeck AR, et al. A prospective cohort study of obesity and risk of oesophageal and gastric adenocarcinoma in the NIH-AARP Diet and Health Study. Gut. 2012; 61:1261-1268. [PubMed: 22174193]

20. Engeland A, Tretli S, Bjorge T. Height and body mass index in relation to esophageal cancer; 23year follow-up of two million Norwegian men and women. Cancer Causes Control. 2004; 15:837843. [PubMed: 15456997]

21. Jacobson BC, Chan AT, Giovannucci EL, et al. Body mass index and Barrett's oesophagus in women. Gut. 2009; 58:1460-1466. [PubMed: 19336423]

22. Stein DJ, El-Serag HB, Kuczynski J, et al. The association of body mass index with Barrett's oesophagus. Aliment Pharmacol Ther. 2005; 22:1005-1010. [PubMed: 16268976]

23. Davey Smith G, Ebrahim S. 'Mendelian randomization': can genetic epidemiology contribute to understanding environmental determinants of disease? Int J Epidemiol. 2003; 32:1-22. [PubMed: 12689998] 
24. Lawlor DA, Harbord RM, Sterne JA, et al. Mendelian randomization: using genes as instruments for making causal inferences in epidemiology. Stat Med. 2008; 27:1133-1163. [PubMed: 17886233]

25. Greenland S. An introduction to instrumental variables for epidemiologists. Int J Epidemiol. 2000; 29:722-729. [PubMed: 10922351]

26. Davey Smith G, Lawlor DA, Harbord R, et al. Clustered environments and randomized genes: a fundamental distinction between conventional and genetic epidemiology. PLoS Med. 2007; 4:e352. [PubMed: 18076282]

27. Davey Smith G, Ebrahim S. What can Mendelian randomisation tell us about modifiable behavioural and environmental exposures? BMJ. 2005; 330:1076-1079. [PubMed: 15879400]

28. Levine DM, Ek WE, Zhang R, et al. A genome-wide association study identifies new susceptibility loci for esophageal adenocarcinoma and Barrett's esophagus. Nat Genet. 2013; 45:1487-1493. [PubMed: 24121790]

29. Kabat GC, Heo M, Miller AB, et al. Scaling of weight for height in relation to risk of cancer at different sites in a cohort of Canadian women. Am J Epidemiol. 2013; 177:93-101. [PubMed: 23139246]

30. Palmer TM, Sterne JA, Harbord RM, et al. Instrumental variable estimation of causal risk ratios and causal odds ratios in Mendelian randomization analyses. Am J Epidemiol. 2011; 173:13921403. [PubMed: 21555716]

31. Staiger D, Stock JH. Instrumental variables regression with weak instruments. Econometrica. 1997; 65:557-586.

32. Baum CF, Schaffer ME, Stillman S. Instrumental variables and GMM: estimation and testing. Stata J. 2003; 3:1-32.

33. Kabat GC, Heo M, Kamensky V, et al. Adult height in relation to risk of cancer in a cohort of Canadian women. Int J Cancer. 2013; 132:1125-1132. [PubMed: 22753236]

34. Albanes D, Winick M. Are cell number and cell proliferation risk factors for cancer? J Natl Cancer Inst. 1988; 80:772-774. [PubMed: 3385783]

35. Hwang AE, Mack TM, Hamilton AS, et al. Childhood infections and adult height in monozygotic twin pairs. Am J Epidemiol. 2013; 178:551-558. [PubMed: 23585330]

36. Thrift AP, Kendall BJ, Pandeya N, et al. A clinical risk prediction model for Barrett esophagus. Cancer Prev Res. 2012; 5:1115-1123.

37. Rubenstein JH, Morgenstern H, Appelman H, et al. Prediction of Barrett's esophagus among men. Am J Gastroenterol. 2013; 108:353-362. [PubMed: 23318485]

38. Thrift AP, Kendall BJ, Pandeya N, et al. A model to determine absolute risk for esophageal adenocarcinoma. Clin Gastroenterol Hepatol. 2013; 11:138-144. [PubMed: 23103823] 


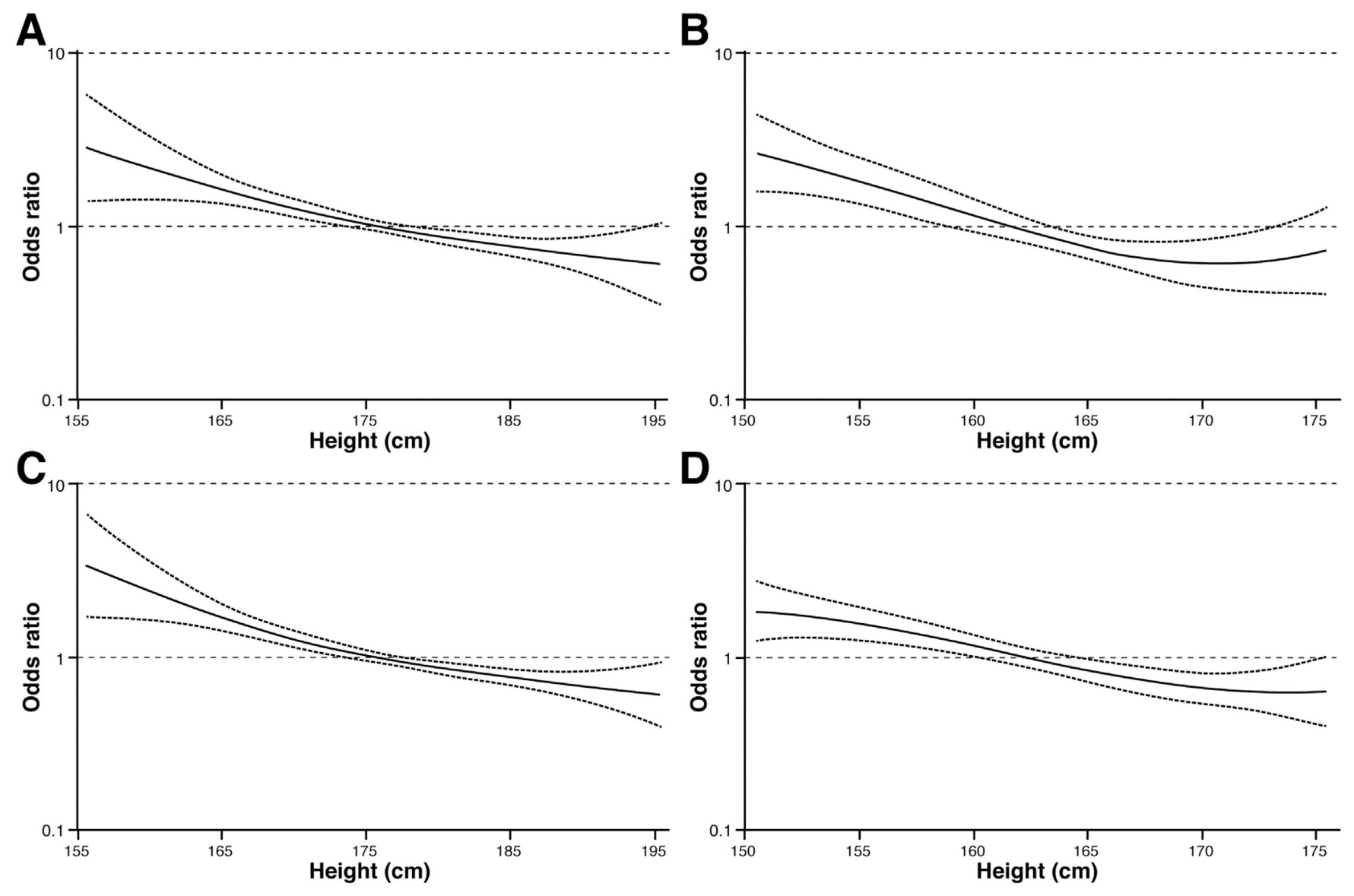

Figure 1.

Restricted cubic spline models of the relationship between height and EAC and BE. $(A)$ EAC in males, $(B)$ EAC in females, $(C) \mathrm{BE}$ in males, and $(D) \mathrm{BE}$ in females. Plots are restricted to heights of 155 to $195 \mathrm{~cm}$ in males and 150 to $175 \mathrm{~cm}$ in females for clarity and consistency. 
A $\quad$ B

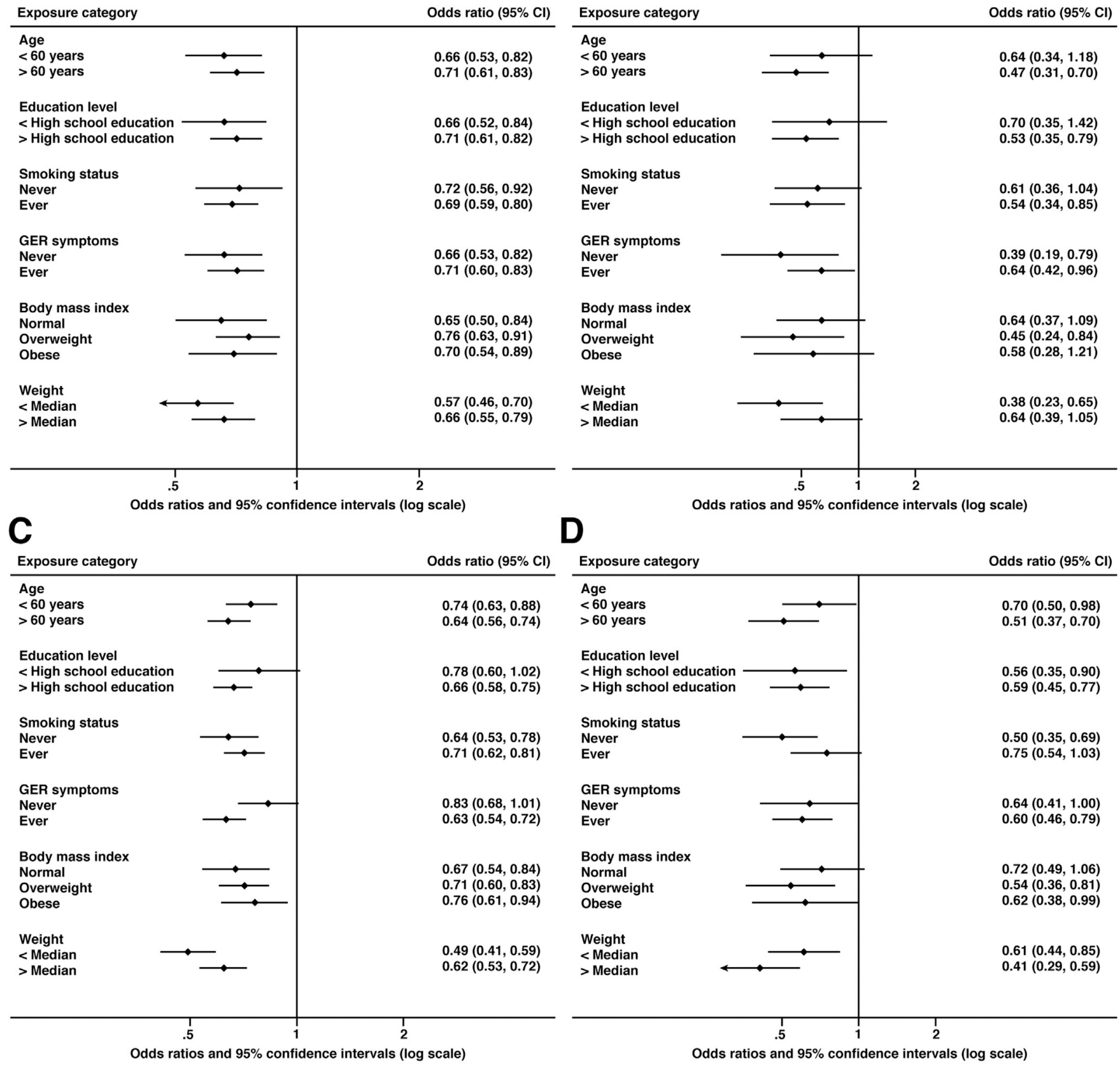

Figure 2.

The summary ORs and 95\% CIs (per 10-cm increase) for associations between height and risks of EAC and BE from stratified analyses. (A) EAC in males, $(B)$ EAC in females, $(C)$ $\mathrm{BE}$ in males, and $(D) \mathrm{BE}$ in females. 
A

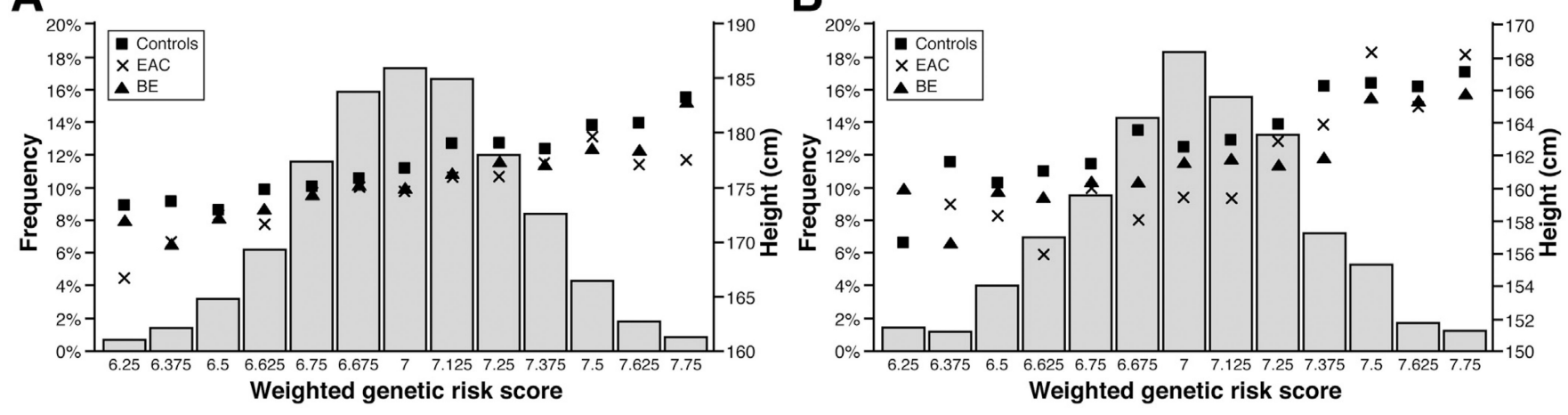

Figure 3.

Distribution of the weighted GRS among all subjects (left y-axis and histogram) and mean height by GRS and case-control status (right y-axis and symbols) for $(A)$ males and $(B)$ females. 


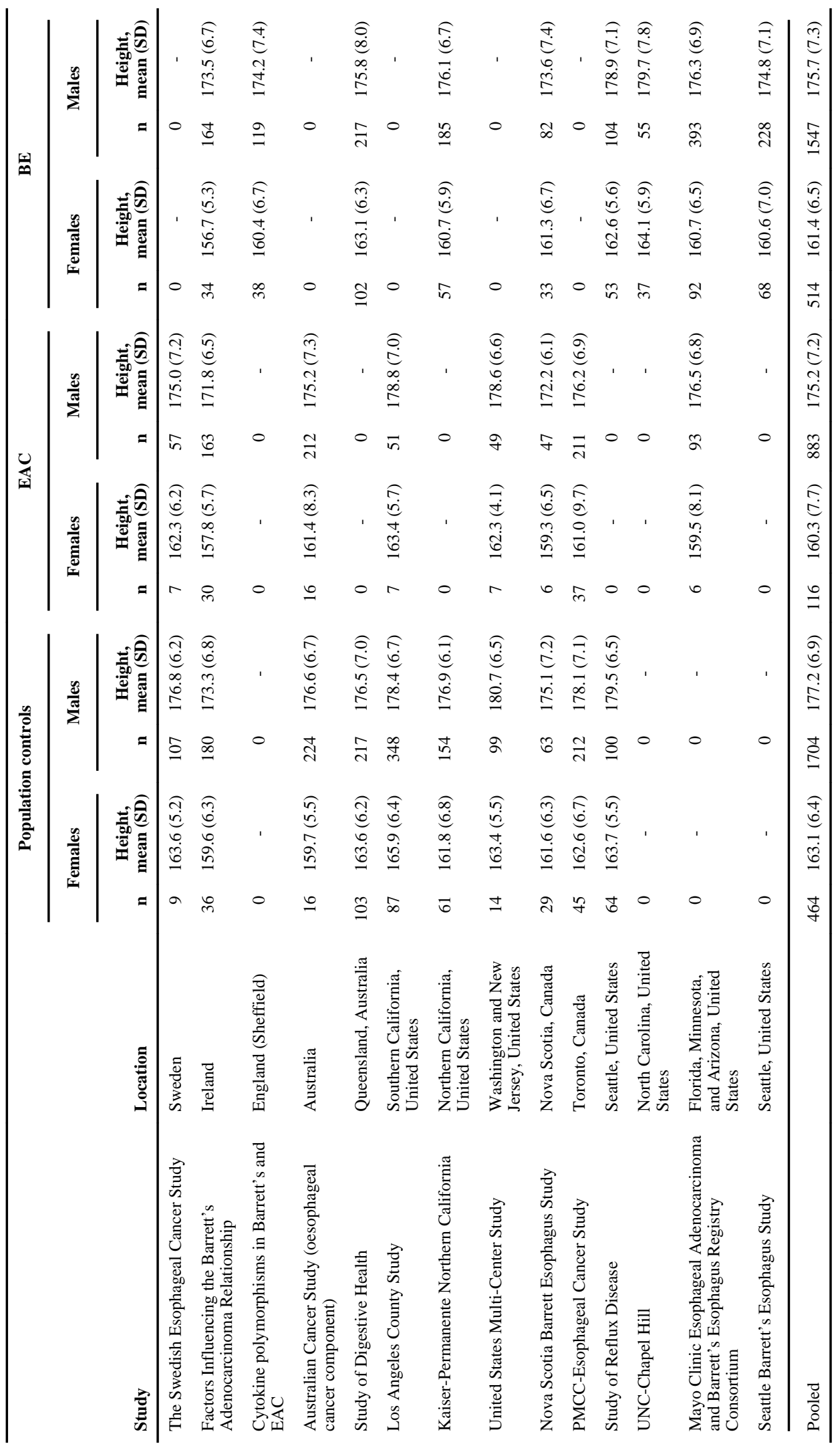


Table 3

ORs and 95\% CIs for the Associations Between Height and EAC and BE

\begin{tabular}{lll}
\hline & OR $^{a}(\mathbf{9 5 \%}$ CI) & OR $^{b}$ (95\% CI) \\
\hline EAC & & \\
Males & & \\
Quartile 1 & $1.00($ Ref $)$ & $1.00($ Ref $)$ \\
Quartile 2 & $0.55(0.44-0.68)$ & $0.55(0.43-0.69)$ \\
Quartile 3 & $0.59(0.47-0.74)$ & $0.61(0.48-0.78)$ \\
Quartile 4 & $0.46(0.36-0.58)$ & $0.48(0.38-0.62)$ \\
Per 10-cm increase & $0.67(0.60-0.76)$ & $0.70(0.62-0.79)$ \\
Females & & \\
Quartile 1 & $1.00($ Ref $)$ & $1.00($ Ref $)$ \\
Quartile 2 & $0.49(0.29-0.83)$ & $0.47(0.27-0.82)$ \\
Quartile 3 & $0.37(0.21-0.66)$ & $0.37(0.20-0.68)$ \\
Quartile 4 & $0.39(0.20-0.75)$ & $0.37(0.18-0.75)$ \\
Per 10-cm increase & $0.59(0.42-0.81)$ & $0.57(0.40-0.80)$ \\
BE & & \\
Males & & \\
Quartile 1 & $1.00($ Ref $)$ & $1.00($ Ref $)$ \\
Quartile 2 & $0.71(0.59-0.86)$ & $0.69(0.57-0.84)$ \\
Quartile 3 & $0.61(0.50-0.74)$ & $0.64(0.52-0.80)$ \\
Quartile 4 & $0.55(0.45-0.67)$ & $0.53(0.43-0.66)$ \\
Per 10-cm increase & $0.71(0.65-0.79)$ & $0.69(0.62-0.77)$ \\
Females & & \\
Quartile 1 & $1.00($ Ref $)$ & $1.00($ Ref $)$ \\
Quartile 2 & $0.89(0.64-1.24)$ & $0.82(0.56-1.19)$ \\
Quartile 3 & $0.58(0.40-0.82)$ & $0.57(0.38-0.85)$ \\
Quartile 4 & $0.50(0.34-0.74)$ & $0.50(0.32-0.78)$ \\
Per 10-cm increase & $0.64(0.52-0.78)$ & $0.61(0.48-0.77)$ \\
\hline & & \\
\hline
\end{tabular}

NOTE. Quartile definitions were as follows: males: $<173 \mathrm{~cm}, 173$ to $<178 \mathrm{~cm}, 178$ to $<182 \mathrm{~cm}$, and $\geq 182 \mathrm{~cm}$; females: $<158 \mathrm{~cm}, 158$ to $<163 \mathrm{~cm}$, 163 to $<168 \mathrm{~cm}$, and $\geq 168 \mathrm{~cm}$.

${ }^{a}$ Adjusted for age (categoric: $<50,50-59,60-69$, and $\geq 70 \mathrm{y}$ ).

${ }^{b}$ Adjusted for age (categoric: $<50,50-59,60-69$, and $\geq 70 \mathrm{y}$ ), education, cigarette smoking, weight/height ${ }^{x}$, and GER; where $x=1.8$ for males and $x=1.5$ for females. 